\title{
Optimal setting of governor parameters of a grid connected micro grid to damp power system oscillations
}

\author{
Narayan Nahak ${ }^{1}$, Omkar Satapathy ${ }^{2}$, Sarbajit Behera $^{3}$, Md Washiullah $^{4}$, Aadarsh Naik $^{5}$ \\ ${ }^{1}$ Department of Electrical Engineering, Siksha 'O' Anusandhan Deemed to be University, India , \\ narayannahak@soa.ac.in \\ 2 Department of Electrical Engineering, Siksha 'O' Anusandhan Deemed to be University, India , \\ omkarsatapathy77.os@gmail.com \\ ${ }^{3}$ Department of Electrical Engineering, Siksha 'O' Anusandhan Deemed to be University, India , \\ sarbajitbehera67@gmail.com \\ ${ }^{4}$ Department of Electrical Engineering, Siksha 'O' Anusandhan Deemed to be University, India , \\ mdwashiullah007@gmail.com \\ ${ }^{5}$ Department of Electrical Engineering, Siksha 'O' Anusandhan Deemed to be University, India , \\ aadarshnaik6@gmail.com
}

\begin{abstract}
Power oscillation damping is a challenging task for a micro grid when connected to grid. Here the micro grid modeling is based on synchronous generation that includes governor \& excitation parameter also. This work proposes that effective setting of governor parameters of micro grid can damp system oscillations heavily pertaining to disturbance such as changes in input mechanical prime mover power. Optimization technique PSO, GWO have been employed to tune governor parameters \& have been compared with proposed hybrid PSO with improved GWO technique in this work. It has been observed in this work that changes in input mechanical power of micro grid excites system oscillations \& the governor with optimal settings of its parameter can efficiently damp these oscillations. Eigen values analysis have been conducted to justify the efficiency of proposed optimal governor \& the control law has been compared with standard techniques \& proposed techniques.
\end{abstract}

Key words: Governor, power system oscillations, turbine, micro grid

\section{INTRODUCTION}

The MG concept has been solving many power qualities issues $\&$ also has been adoptable pertaining to reliability \& economic operation of power system including voltage $\&$ frequency stabilities [1]. The crisis in conventional energy needs energy management and a technique is presented in [2]. But, dynamic interaction of low inertia MG with existing grid has been a challenging issue for power system operators. In [3] synchronization of a grid connected PV system is presented. The MG may be based on synchronous, induction generator or generations based on power electronics-based converters. The stability study with MG penetration in low frequency domain demands linear modelling of $\mathrm{MG}$ components with existing power system. Many researches have been done regarding linear model of power system [4], [5]. The Heffron-Philips transfer function model has been adopted by many researchers for linear model of power system [6]-[8] for single multi machine system based on synchronous generation. Generalized model of $\mathrm{MG}$ in this regard has been performed in [9]. In [10] the MG model is based on KVL \& KCL. But, estimation of MG parameters along with control actions were presented in [11], [12]. In [13] the estimation of parameters has been proposed on measurement basis. Researchers have proposed several techniques pertaining to equivalent modeling of MG. Such kind of approaches employing black-box theory being presented in [14]-[16]. The equivalencing may employ mathematical or dynamic modelling of MGs as reported in [17], [18]. A linear equivalent model of MG with grid connected has been reported in [19] employing modifications in Heffron Phillips model. In this model governor \& excitation systems have been also included which can be used to study of power system stability in low frequency domain. But the next issue is implementation of this model for enhancing small signals stability. In this work the governor parameters are employed with the effective optimal settings to damp oscillations of such grid connected micro grid subject to variation in input mechanical power. For tuning governor parameters an efficient hybrid PSO-IGWO technique [20] has been proposed which has been compared with PSO \& GWO techniques.

\section{SYNCHRONOUS GENERATOR BASED MG MODELING}

The model of MG includes modeling of turbine, governor and excitation systems. Modified Heffron-phillips model has been implemented for MG modeling[19]. The Figure 1 and Figure 2 present standard IEEE-ST6B excitation system and turbine governor modeling respectively

In this work the initial operating condition is taken as $\mathrm{P}_{\mathrm{o}}=0.8$ pu and $\mathrm{Q}_{0}=0.17 \mathrm{pu}$. In this model, the excitation system (EEXS) and turbine governor system are also included. The state equations describing the model are given as:

$$
\frac{d w}{d t}=\frac{1}{2 H}\left(T_{m}-T_{e}-T_{D}\right)
$$




$$
\begin{aligned}
& \frac{d \delta}{d t}=\omega_{b}(\omega-1) \\
& \frac{d e_{q}^{\prime}}{d t}=\frac{1}{T_{d 0}^{\prime}}\left[E_{f d}-e_{q}^{\prime}-\left(X_{d}-X_{d}^{\prime}\right) i_{d}\right] \\
& i=i_{d}+j i_{q} \\
& v_{t}=v_{d}+j v_{q} \\
& V_{p c c}=v_{p c c}(\sin \delta+j \cos \delta) \\
& Z=R+j X Y=G+j B \\
& C_{1}+j C_{2}=1+Z Y \\
& R_{1}=R-C_{2} X_{d}^{\prime}, R_{2}=R-C_{2} X_{q} \\
& X_{1}=X+C_{1} X_{q}, R_{2}=R-C_{2} X_{q} \\
& X_{1}=X+C_{1} X_{q}, X_{2}=X+C_{1} X_{d}^{\prime} \\
& Z_{e}^{2}=R_{1} R_{2}+X_{1} X_{2} \\
& Y_{d}=\left(C_{1} X_{1}-C_{2} R_{2}\right) / Z_{e}^{2} \\
& Y_{q}=\left(C_{1} R_{1}-C_{2} X_{2}\right) / Z_{e}^{2} \\
& v_{d o}=P_{o} v_{t 0}\left[P_{0}^{2}+\left(Q_{0}^{2}+v_{t 0}^{2} / X_{q}\right)^{2}\right]^{-1 / 2} \\
& V_{q 0}=\left(V_{t 0}^{2}-V_{d}^{2}\right)^{1 / 2} \\
& i_{q 0}=\frac{v d 0}{X_{q}} i_{d 0}=\left(P_{0}-i_{q 0} v_{q 0}\right) / v_{d 0} \\
& e_{q 0}^{\prime}=v_{q 0}+X_{d}^{\prime} i_{d 0} \\
& v_{p c c d 0}=C_{1} v_{d 0}-C_{2} v_{q 0}-R i_{d 0}+X i_{q 0} \\
& v_{p c c q 0}=C_{2} v_{d 0}+C_{1} v_{q 0}-X i_{d 0}-R i_{q 0} \\
& \delta_{0}=\tan ^{-1}\left(\frac{v_{p c c d 0}}{v_{p c c q 0}}\right) \\
& i_{L d 0}=G v_{d 0}-B v_{q 0} i_{L q 0}=G v_{q 0}+B v_{d 0} \\
& i_{\text {Lined } 0}=i_{d 0}-i_{L d 0} i_{\text {Lineq } 0}=i_{q 0}-i_{L q 0}
\end{aligned}
$$

By Kirchoff's voltage law te parameters are presented as: $Z i=(1+Z Y) v_{t}-v_{p c c}$

$$
\left[\begin{array}{cc}
R & -X \\
X & R
\end{array}\right]\left[\begin{array}{l}
i_{d} \\
i_{q}
\end{array}\right]=\left[\begin{array}{cc}
C_{1} & -C_{2} \\
C_{2} & C_{1}
\end{array}\right]\left[\begin{array}{l}
v_{d} \\
v_{q}
\end{array}\right]-v_{p c c}\left[\begin{array}{l}
\sin \delta \\
\cos \delta
\end{array}\right]
$$

As per $[23,24]$ the voltage and currents in $d$ and $q$ axis are stated as:

$$
\left[\begin{array}{c}
v_{d} \\
v_{q}
\end{array}\right]=\left[\begin{array}{l}
0 \\
1
\end{array}\right] e_{q}^{\prime}-\left[\begin{array}{cc}
0 & -X_{q} \\
X_{d}^{\prime} & 0
\end{array}\right]\left[\begin{array}{l}
i_{d} \\
i_{q}
\end{array}\right]
$$

By combining Eq-4 and Eq-5 the equations are presented as

$$
\left[\begin{array}{l}
i_{d} \\
i_{q}
\end{array}\right]=\left[\begin{array}{l}
Y_{d} \\
Y_{q}
\end{array}\right] e_{q}^{\prime}-\frac{v_{p c c}}{Z_{e}^{2}}\left[\begin{array}{cc}
R_{2} & X_{1} \\
-X_{2} & R_{1}
\end{array}\right]\left[\begin{array}{c}
\sin \delta \\
\cos \delta
\end{array}\right]
$$

And which can be linearized as

$$
\left[\begin{array}{c}
\Delta i_{d} \\
\Delta i_{q}
\end{array}\right]=\left[\begin{array}{l}
Y_{d} \\
Y_{q}
\end{array}\right] \Delta e_{q}^{\prime}+\left[\begin{array}{c}
F_{d} \\
F_{q}
\end{array}\right] \Delta \delta
$$

For which

$$
\left[\begin{array}{c}
F_{d} \\
F_{q}
\end{array}\right]=\frac{v_{p c c}}{Z_{e}^{2}}\left[\begin{array}{cc}
-R_{2} & X_{1} \\
X_{2} & R_{1}
\end{array}\right]\left[\frac{\cos \delta_{0}}{\sin \delta_{0}}\right] \Delta e_{q}^{\prime}
$$

In the Heffron -Phillips model the input signals have the relations with the variables by the K-constants. So the torque and real powers are presented Eq-5

$$
\begin{aligned}
& T_{e}=p=i_{d} v_{d}+i_{q} v_{q} \\
& \Delta T_{e}=K_{1} \Delta \delta+K_{2} \Delta e_{q}^{\prime} \\
& {\left[\begin{array}{c}
K_{1} \\
K_{2}
\end{array}\right]=\left[\begin{array}{c}
0 \\
i_{q 0}
\end{array}\right]+\left[\begin{array}{ll}
F_{d} & F_{q} \\
Y_{d} & Y_{q}
\end{array}\right]\left[\begin{array}{c}
\left(X_{q}-X_{d}\right) i_{q 0} \\
e_{q o}^{\prime}+\left(X_{q}-X_{d}^{\prime}\right) i_{d 0}
\end{array}\right]}
\end{aligned}
$$

The equation of internal voltage in Eq-1 is linearized as

$\left(1+s T_{d 0}^{\prime}\right) \Delta e_{q}^{\prime}=\Delta E_{f d}-\left(X_{d}-X_{d}^{\prime}\right) \Delta i_{d}$

And using Eq-7 we can write Eq-11 as:

$$
\begin{aligned}
& \left(1+s T_{d 0}^{\prime}\right) \Delta e_{q}^{\prime}=K_{3}\left[\Delta E_{f d}-K_{4} \Delta \delta\right] \\
& K_{3}=1 /\left[1+\left(X_{d}-X_{d}^{\prime}\right) Y_{d}\right] \\
& K_{4}=\left(X_{d}-X_{d}^{\prime}\right) F_{d}
\end{aligned}
$$

The state variables can be linked with output reactive power as Eq-12.

$$
\begin{aligned}
& Q=i_{d} v_{q}-i_{q} v_{d} \\
& \Delta Q=K_{5} \Delta \delta \mathrm{Z}+K_{6} \Delta e_{q}^{\prime} \\
& {\left[\begin{array}{c}
K_{5} \\
K_{6}
\end{array}\right]=\left[\begin{array}{c}
0 \\
i_{d 0}
\end{array}\right]+\left[\begin{array}{ll}
F_{d} & F_{q} \\
Y_{d} & Y_{q}
\end{array}\right]\left[\begin{array}{c}
e_{q 0}^{\prime}-2 X_{d} i_{d 0} \\
-2 X_{q} i_{q 0}
\end{array}\right]}
\end{aligned}
$$

In the above equations $K_{1}$ to $K_{5}$ are constants of constants of Heffron-Phillips model for SG. Finally the SG based grid connected MG can be modeled as in Figure 3 employing Eq (9), (11) and (12). Figure 4 shows MG with infinite bus. The real and reactive power and their changes at the point of common coupling can be presented as Eq-13 and Eq-14:

$$
\begin{aligned}
& P_{p c c}=v_{p c c} i_{\text {Lined }}+v_{p c c q} i_{\text {Lineq }} \\
& Q_{p c c}=v_{p c c} i_{\text {Lined }}-v_{p c c d} i_{\text {Lineq }} \\
& \Delta P_{p c c}=\Delta v_{p c c} i_{\text {Lined } 0}+v_{p c c d 0} \Delta i_{\text {Lined }}+\Delta v_{p c c q} i_{\text {Lined }}+v_{p c c q 0} \Delta i_{\text {Lineq }}
\end{aligned}
$$$$
\Delta Q_{p c c}=\Delta v_{p c c q} i_{\text {Lined } 0}+v_{p c c q 0} \Delta i_{\text {Lined }}-\Delta v_{p c c d} i_{\text {Lineq } 0}-v_{p c c d 0} \Delta i_{\text {Lineq }}
$$ 


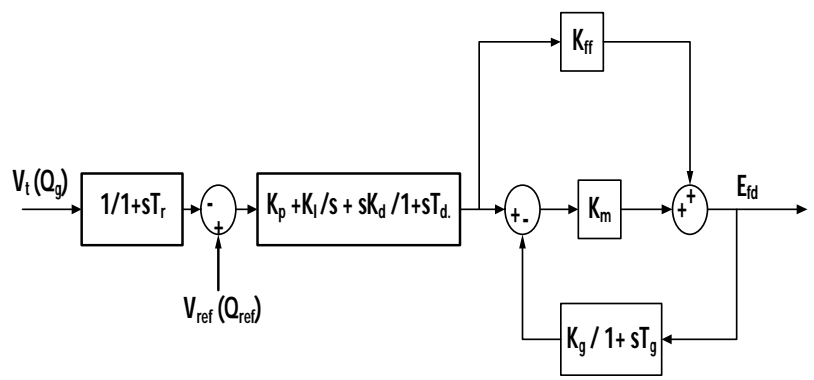

Figure 1:. IEEE-ST6B excitation system

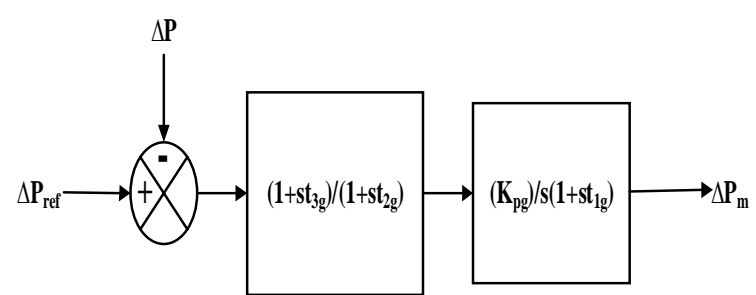

Figure 2: Equivalent turbine governor modeling

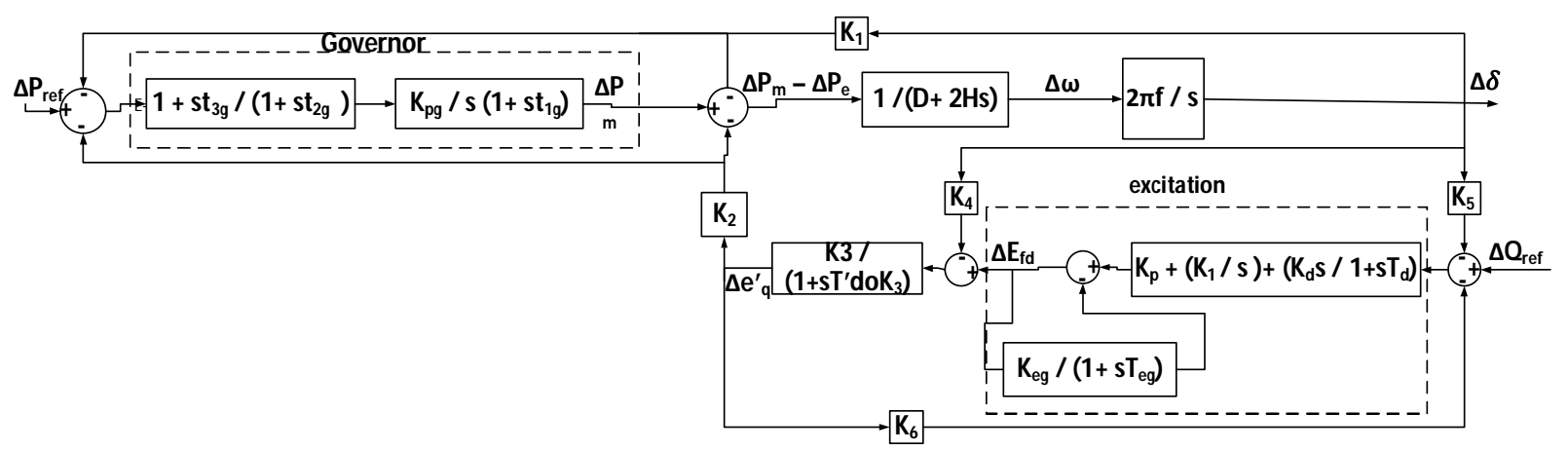

Figure 3: Modeling of microgrid

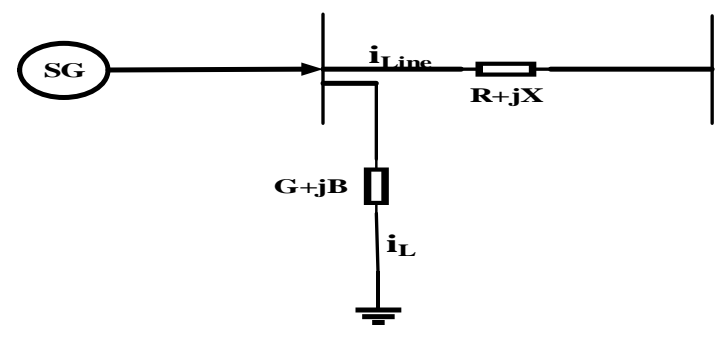

$\mathbf{J}$ is to be minimized considering the constraints in parameters. The gains range is taken from 1 to 10 for $\mathrm{K}_{\mathrm{pg}}, 0.1$ to 1 for $t_{1 g}, t_{2 g}, t_{3}$.

\section{HYBRID PSO-IGWO ALGORITHM}

According to the researched study, PSO is very basic and can be executed effectively thus most powerful to varieties in parameters. GWO providing a very good balancing in exploration \& exploitations, simplifying calculations. PSO \& GWO has chances of getting trapped in the local minima. IGWO adding an additional element to GWO for avoiding of getting trapped with changed hunt operations. So, the controlling law has been motivating by the hybridising of PSO \& IGWO in order of avoiding of getting trapped in local optima and having persistent global optimisation subjected to the critically solar integration power system. This work proposing this hybridising optimisation algorithm for the elimination of the optimising values of the UPFC controlling gains. For having the optimal valuating of the controlling gains ; this hybridisation PSO-IGWO (20)strategy is applied in this work. The approach of the hybridising technique is shown in the flow chart in Figure 5.

For PSO the swarm velocity and position are given by

$v_{i}^{k+1}=w v_{i}^{k}+c_{1} \operatorname{rand}_{1}\left(P_{i, p b e s t}^{k}-x_{i}^{k}\right)+c_{2} \operatorname{rand}_{2}\left(P_{i, g b e s t}^{k}-x_{i}^{k}\right)$

The speed deviation $\Delta \omega$ is to be minimized as given by Eq15 below:

$$
J=\int_{0}^{t s i m} t|\Delta \omega| d t
$$

Subject to constraints

$$
\begin{aligned}
& \mathrm{K}_{\mathrm{pg}}^{\min } \leq \mathrm{K}_{\mathrm{pg}} \leq \mathrm{K}_{\mathrm{pg}}{ }_{\max } \text {, } \\
& \mathrm{t}_{1 \mathrm{~g}}^{\min } \leq \mathrm{t}_{1 \mathrm{~g}} \leq \mathrm{t}_{1 \mathrm{~g}}{ }_{\text {max }}, \mathrm{t}_{2 \mathrm{~g}}^{\min } \leqslant \mathrm{t}_{2 \mathrm{~g}} \leqslant \mathrm{t}_{2 \mathrm{~g}}^{\max } \\
& \mathrm{t}_{3 \mathrm{~g}} \text { min } \leqslant \mathrm{t}_{3 \mathrm{~g}} \leqslant \mathrm{t}_{3 \mathrm{~g}} \text { max }
\end{aligned}
$$

For IGWO update position of alpha ,beta and delta wolfs are given by 


$$
\begin{aligned}
& \vec{D}_{\alpha}=\left|\vec{C}_{1} \cdot \vec{X}_{\alpha}-\vec{X}\right|, \vec{D}_{\beta}=\left|\vec{C}_{2} \cdot \vec{X}_{\beta}-\vec{X}\right|, \vec{D}_{\delta}=\left|\vec{C}_{3} \cdot \vec{X}_{\delta}-\vec{X}\right| \\
& \vec{X}_{1}=\vec{X}_{\alpha}-\vec{A}_{1} \cdot\left(\vec{D}_{\alpha}\right), \vec{X}_{2}=\vec{X}_{\beta}-\vec{A}_{2} \cdot\left(\vec{D}_{\beta}\right), \vec{X}_{3}=\vec{X}_{\delta}-\vec{A}_{3} \cdot\left(\vec{D}_{\delta}\right)
\end{aligned}
$$

The final position is presented by

$$
\vec{X}(t+1)=\frac{\vec{X}_{1}+\vec{X}_{2}+\vec{X}_{3}}{3}
$$

The steps which is describing the fulfilment of this algorithm are stated beneath:-

Step1:-Initializing the size[NpXD] of randomised population. Step2:-Initialising for every particles involving in the PSO algorithm of the randomised positioning and velocity.

\section{Step3:-PSO Operation}

- $\quad$ Evaluating the fitness function for each particles basing of the objective function

- $\quad$ Computing of each best (P best) \& globally best ( $\mathrm{G}$ best).

- Updating of velocities of each swarm

- $\quad$ Updating of the swarm positioning computed fitness values of each particles based on the objective functioning

- Choose the best solution for the next iteraised fitness value for comparing

Step4:- IGWO operations

- $\quad$ Considering the initial population of IGWO as the finalised population of PSO.

- $\quad$ A,C\& a are updated.

- $\quad$ Generating random positioning of each searching

agent.

- Use of objective function for computing the fitness values of grey wolves

- Update of positioning of grey wolves D' $\alpha, D^{\prime} \beta, D^{\prime} \delta$.

- $\quad$ Comparing of fitness function by selecting the best solution for the next iteration.

- $\quad$ Update of $\mathrm{X} \alpha, \mathrm{X} \beta, \mathrm{X} \delta$. population.

Update the finalised positioning of the total

Unless stopping criterion reaching continuing steps Step 5:-Obtain finalised optimum values of the controlled parameter.

\section{RESULT AND DISCUSSION}

In this work optimal governor action is proposed to damp low frequency oscillations. To justify the effect of governor action on stability different cases have been considered in this work. ITAE type objective function has been taken to optimize governor parameters. PSO, IGWO and hPSOIGWO algorithms are employed to tune governor gains and hPSO-IGWO is proposed here. The initial operating condition is $0.8 \mathrm{pu}$ for real power and 0.17 pu reactive power generation. The disturbance taken here is change in input power to generator. In case-1, the input power is suddenly changed by $1 \%$. In case- 2 the input power is suddenly changed by $5 \%$ and in case- 3 the input power is suddenly changed by $10 \%$. Figure 6 presents deviations in speed for three cases without governor control actions and Table-1 shows corresponding damping response parameters. This shows that oscillations are much aggravated without governor actions. Figure 7 and Figure 8 present real power and speed deviations for case-1, Figure 9 and Figure 10 present speed deviations for case- 2 and case- 3 with proposed governor action and system eigen values are given in Table2. It is observed that system oscillations being much enhanced with sudden rise of input power by a large extent and governor is able to damp system oscillations. Also optimization of governor gains are compared with PSO and IGWO optimizations. It is observed that hybrid PSO and IGWO algorithm enhances the damping capability of governor by a large extent. 


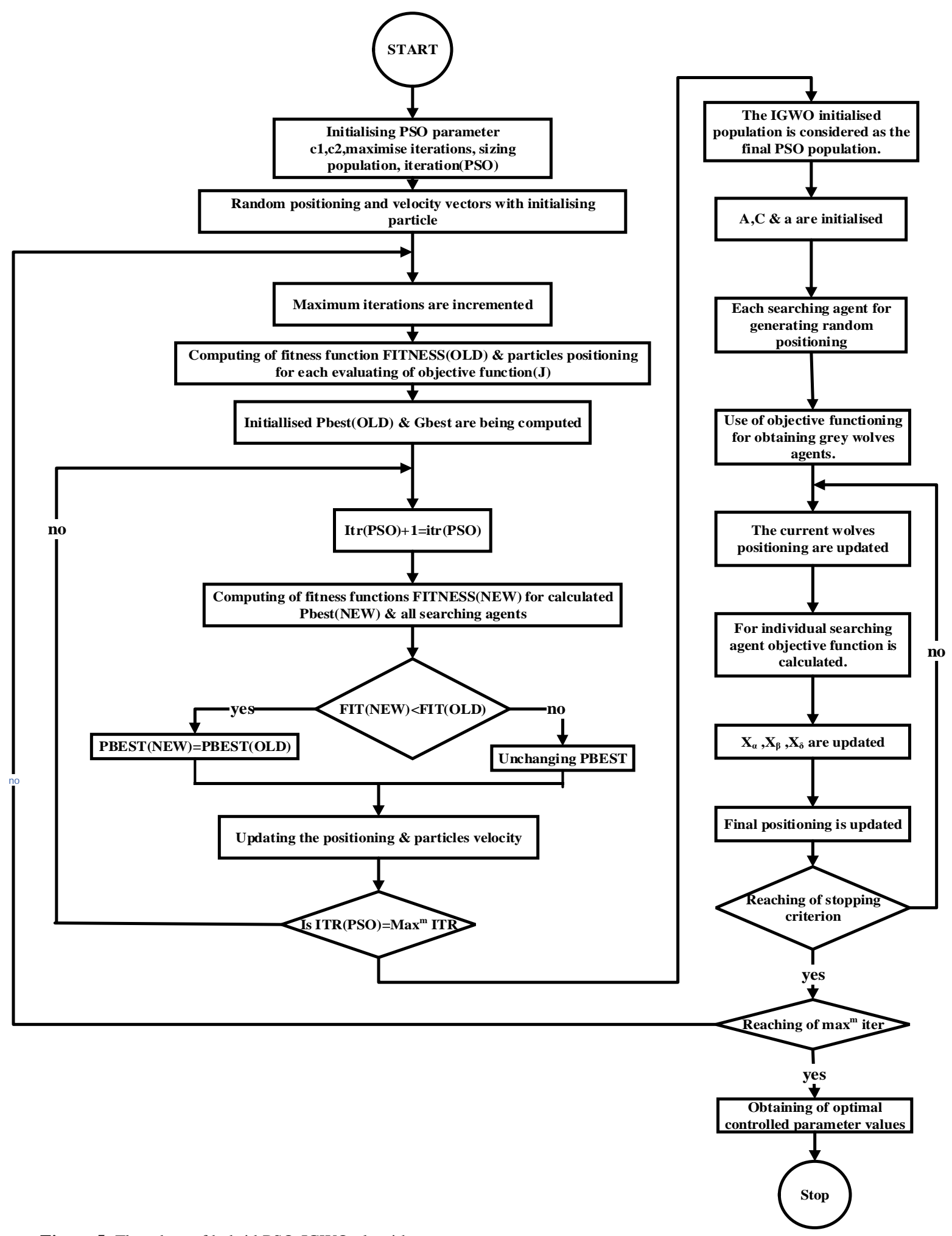

Figure 5: Flowchart of hybrid PSO-IGWO algorithm 
Narayan Nahak et al., International Journal of Emerging Trends in Engineering Research, 8(6), June 2020, 2577- 2584

Table 2: System eigen values

\begin{tabular}{|c|c|c|}
\hline \multicolumn{3}{|c|}{ Case-1 } \\
\hline PSO & IGWO & hPSO-IGWO \\
\hline-3.6441 & -4.4341 & -6.6761 \\
\hline-0.6712 & -0.7623 & -0.8912 \\
\hline-1.2679 & -1.2879 & -1.6879 \\
\hline$-1.3223+4.2792 \mathrm{i}$ & $-3.3223+2.7792 \mathrm{i}$ & $-4.3223+1.0172 \mathrm{i}$ \\
\hline$-1.3223-4.2792 \mathrm{i}$ & $-3.3223-2.7792 \mathrm{i}$ & $-4.3223-1.0172 \mathrm{i}$ \\
\hline-0.9884 & -0.9464 & -0.9783 \\
\hline-0.9518 & -0.9543 & -0.9898 \\
\hline-16.2071 & -17.2086 & -21.1020 \\
\hline-13.0848 & -13.0986 & -19.0864 \\
\hline-0.5556 & -0.5576 & -0.5673 \\
\hline 0 & 0 & 0 \\
\hline-0.1000 & -0.1000 & -0.1000 \\
\hline \multicolumn{3}{|c|}{ Case-2 } \\
\hline-3.6764 & -3.9829 & -6.4921 \\
\hline-0.7621 & -0.9829 & -0.9533 \\
\hline-1.7626 & -2.7674 & -2.6231 \\
\hline$-1.3433+3.2312 \mathrm{i}$ & $-3.8733+2.0112 \mathrm{i}$ & $-4.4623+0.9971 \mathrm{i}$ \\
\hline$-1.3433-3.2312 \mathrm{i}$ & $-3.8733-2.0112 \mathrm{i}$ & $-4.4623-0.9971 \mathrm{i}$ \\
\hline-0.9884 & -0.8984 & -0.9863 \\
\hline-0.9589 & -0.9119 & -0.9776 \\
\hline-17.2642 & -18.2642 & -22.2310 \\
\hline-14.4348 & -15.4348 & -20.1208 \\
\hline-0.7836 & -0.7436 & -0.6632 \\
\hline 0 & 0 & 0 \\
\hline-0.1000 & -0.1000 & -0.1000 \\
\hline \multicolumn{3}{|c|}{ Case-3 } \\
\hline-4.6764 & -4.8810 & -7.4921 \\
\hline-0.8770 & -1.0231 & -1.0001 \\
\hline-2.2069 & -2.9001 & -3.2623 \\
\hline$-2.0312+2.2234 \mathrm{i}$ & $-3.9901+1.8011 \mathrm{i}$ & $-5.3101+0.6790 \mathrm{i}$ \\
\hline$-2.0312-2.2234 \mathrm{i}$ & $-3.9901+1.8011 \mathrm{i}$ & $-5.3101-0.6790 \mathrm{i}$ \\
\hline-1.0412 & -0.9023 & -0.9770 \\
\hline-0.9511 & -0.8912 & -0.9764 \\
\hline-17.8901 & -18.7877 & -23.2121 \\
\hline-16.0021 & -15.4331 & -21.6312 \\
\hline-0.7101 & -0.7000 & -0.7000 \\
\hline 0 & 0 & 0 \\
\hline-0.1000 & -0.1000 & -0.1000 \\
\hline
\end{tabular}

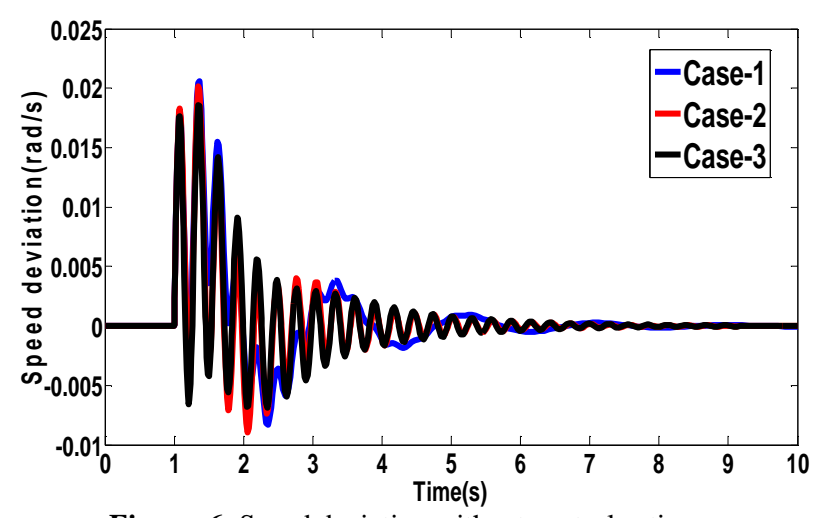

Figure 6: Speed deviation without control action

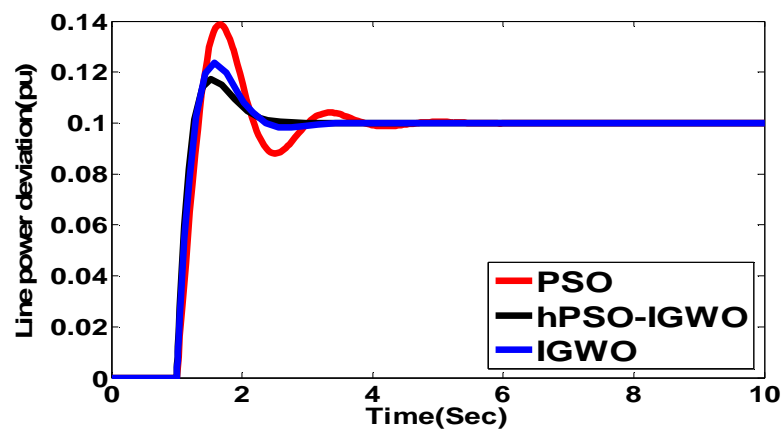

Figure 7: Real power deviation for case-1

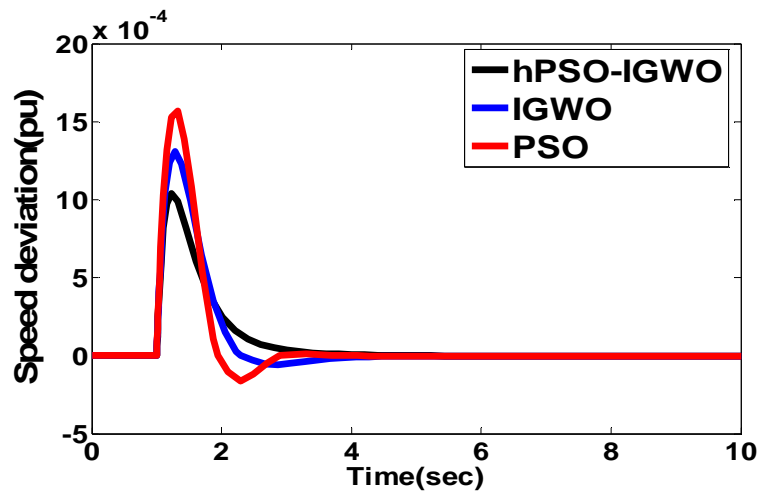

Figure 8:Speed deviation for case-1

Table 1: Optimal governor parameters

\begin{tabular}{|c|c|c|c|c|}
\hline Algorithms & Kpg & t1g & t2g & t3g \\
\hline PSO & 1.1106 & 0.1583 & 0.4948 & 0.2100 \\
\hline IGWO & 6.935 & 0.1933 & 0.8619 & 0.8289 \\
\hline PSO-IGWO & 4.4991 & & & 0.9138 \\
\hline
\end{tabular}




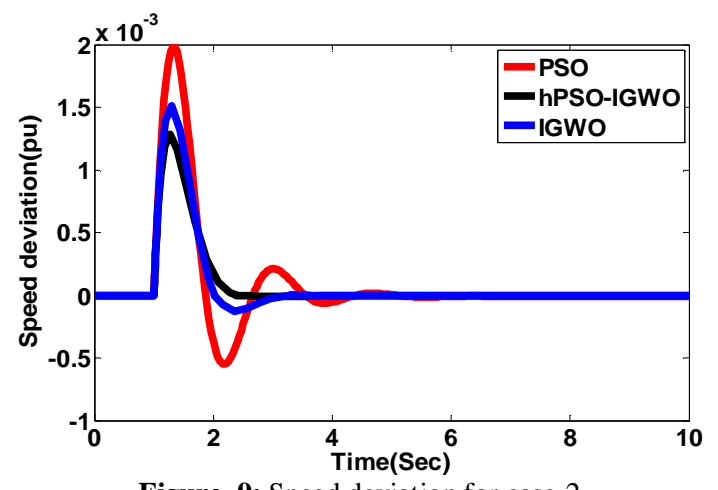

Figure 9: Speed deviation for case-2

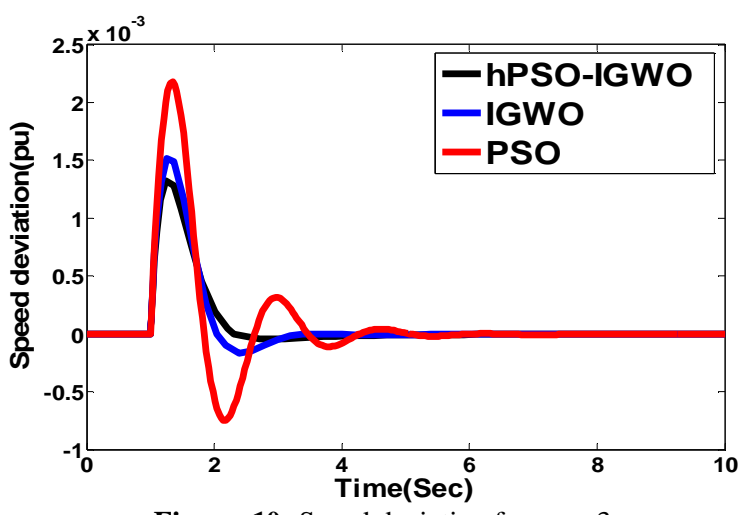

Figure 10: Speed deviation for case-3

\section{CONCLUSION}

In this work optimal setting of governor parameters is proposed for a grid connected synchronous generator based micro grid for damping power system oscillations. The disturbance considered here is step change in input mechanical power. The governor parameters are tuned by hybrid PSO with improved GWO technique. It is observed that governor has the capability to damp oscillations much efficiently and optimal setting of its parameters can enhance its efficacy by a large extent. Also parameter tuning by proposed algorithm provides much better response in contrast to standard PSO and improved GWO algorithms.

\section{REFERENCES}

[1] A.Anilkumar, N.V.Srikanth, Teaching Learning Optimization Based Adaptive Fuzzy Logic Controller for Frequency Control in an Autonomous Microgrid. International journal of renewable energy research Vol.7, No.4, 2017

[2] Elmer R. Magsino, Energy Monitoring System Incorporating Energy Profiling and Predictive Household Movement for Energy Anomaly Detection, International Journal of Emerging Trends in Engineering Research, Volume 7, No. 8 August 2019 https://doi.org/10.30534/ijeter/2019/08782019

[3] A. Satif, L. Hlou, H. Dahou, M. Mekhfioui, R. Elgouri, Grid-connected photovoltaic systems synchronization algorithms under disturbances: a low-cost hardware implementation using Arduino DUE, International
Journal of Emerging Trends in Engineering Research, Volume 8, No. 3 March 2020.

https://doi.org/10.30534/ijeter/2020/11832020

[4] Undrill JM, Turner AE. Construction of power system electromechanical equivalents by modal analysis. IEEE Trans Power Apparat Syst 1971;90(Sept.):2049-59.

[5] de Oliveira SEM, de Queiroz JF. Modal dynamic equivalent for electric power systems. I. Theory. IEEE Trans Power Syst 1988;3(Nov.):1723-30.

[6] Zaker B, Gharehpetian GB, Moaddabi N. Parameter identification of Heffron-Phillips model considering AVR using on-line measurements data. International. Conference on Renewable Energies and Power Quality (ICREPQ'14), Cordoba, Spain, April 8-10, 2014. 2014.

[7] Dehghani M, Nikravesh SKY. State-space model parameter identification in largescale power systems. IEEE Trans Power Syst 2008;23(3):1449-57. https://doi.org/10.1109/TPWRS.2008.922632

[8] Ghahremani E, Karrari M, Malik OP. Synchronous generator third-order model parameter estimation using on-line experimental data. IET Gener Transm Distrib 2008;2(5):708-19.

[9] Preda TN, HadjSaid N. Dynamic equivalents of active distribution grids based on model parameters identification. In: PES general meeting conference \& exposition, 2014 IEEE, 27-31 July 2014. p. 1-5

[10] Changchun C, Xiangqin C. Equivalent simplification method of micro-grid. TELKOMNIKA 2013;11(9):5461-70

[11]Zaker B, Gharehpetian GB, Karrari M, Moaddabi N. Simultaneous parameter identification of synchronous generator and excitation system using online measurements. IEEE Trans Smart Grid 2016;7(3):1230 8.

[12]Zaker B, Gharehpetian GB, Karrari M. Improving synchronous generator parameters estimation using $\mathrm{d}-\mathrm{q}$ axes tests and considering saturation effect. IEEE Trans Ind Inf 2018;14(5):1898-1908.

[13] Ju P, Ni LQ, Wu F. Dynamic equivalents of power systems with online measurements. Part 1: Theory. IEE Proc - Gener, Transm Distrib 2004;151(2):175-8. 2 Mar. 2004. https://doi.org/10.1049/ip-gtd:20040095

[14] Papadopoulos PN, Papadopoulos TA, Crolla P, Roscoe AJ, Papagiannis GK, Burt GM. Measurement-based analysis of the dynamic performance of microgrids using system identification techniques. IET Gener Transm Distrib 2015;9(1):90-103.

[15] Azmy AM, Erlich I, Sowa P. Artificial neural networkbased dynamic equivalents for distribution systems containing active sources. IEE Proc Gener, Transm Distrib 2004;151(6):681-8. 12 Nov. 2004.

[16] Azmy AM, Erlich I. Identification of dynamic equivalents for distribution power networks using recurrent ANNs. In: Power systems conference and exposition, 2004. IEEE PES, 10-13 Oct. 2004.pp. 34853.

[17] Milanovic JV, Mat Zali S. Generic model of active distribution network for large power system stability studies. IEEE Trans Power Syst 2013;28(3):3126-33.

[18] Milanovic JV, Mat Zali S. Validation of equivalent dynamic model of active distribution Network Cell. IEEE Trans Power Syst 2013;28(3):2101-10. 
Narayan Nahak et al., International Journal of Emerging Trends in Engineering Research, 8(6), June 2020, 2577- 2584

https://doi.org/10.1109/TPWRS.2012.2227844

[19] B. Zaker, G.B. Gharehpetian, M. Karrari, Small signal equivalent model of synchronous generator-based grid connected microgrid using improved Heffron-Phillips model, Electrical Power and Energy Systems 108 (2019) $263-270$

[20] N. Nahak and R. K. Mallick, "Investigation and damping of low-frequency oscillations of stochastic solar penetrated power system by optimal dual UPFC," in IET Renewable Power Generation, vol. 13, no. 3, pp. 376388, 252 2019, doi: 10.1049/iet-rpg.2018.5066. 